\title{
Research on Impact of Distributed Generation Based on Distribution Network
}

\author{
Qishun Zhu \\ Electrical Engineering and Automation \\ Shenyang Institute of Engineering, \\ Shenyang, China \\ wangjian_shm @163.com \\ Minghao Zhang \\ Branch of Electric Power Transformation, \\ Liaoning State Grid Electric Power Transmission \\ \& Transformation Engineering Company \\ Shenyang, China \\ zhangminghao2008@126.com
}

\author{
Xin Sun \\ Electric Power Research Institute, State Grid Liaoning \\ Electric Power Supply Co. Ltd \\ Shenyang, China \\ sx318@126.com \\ Chengming Jin \\ Information and Communication Branch State Grid \\ Liaoning Electric Power Supply Co. Ltd \\ Shenyang, China \\ jcm@ln.sgcc.com.cn
}

\begin{abstract}
With the rapid development of economy, the power system has also been a rapid development, the whole social also made a lot of the higher requirements. Today's society requires power supply reliability and safety of increasingly high quality, large power due to their own shortcomings can not meet this requirement. With its many advantages of distributed generation in power systems occupy more and more of the share, become an important direction of development in the energy sector, and more and more attention around the world. With the large scale introduction of distributed generation, this will have a significant impact on the existing distribution system. This paper introduces the concept and classification of distributed generation, impact of distributed generation on distribution network, and describes several major DG technologies receiving more attention in detail, the arising impact of several important aspects on the distribution network after DG access distribution network. DG impact on the entire power system would be enormous and far-reaching.
\end{abstract}

Keywords- development; impact; distribution;DG

\section{INTRODUCTION}

Due to the increasing failure of the earth's resources and the growing concern for environmental issues, reform of the power system is a global scale. If the electricity market is a major reform of the electricity industry, then distributed generation is considered to be a major reform of the electricity technology and both effects together make power industry present a whole new look. With the development of the power system, distributed generation can provide a kind of "self-reliance" choice for some users, it can adapt to volatile electricity market. Therefore, after a competitive electricity market to establish, the role of distributed generation will become increasingly apparent and important, which can be combined to form a more efficient and flexible new power system with the existing power system, improving energy efficiency of the whole society and stability, reliability and quality of the entire power system[1].

Diversification of energy and development of renewable energy sources are the fundamental way to meet energy needs. Distributed generation not only play an important complement to centralized power generation but also play a very important role in the energy utilization. Either as a supplement of city power supply or solving the problem of electricity in remote and rural areas, distributed generation has a huge potential market, very broad application prospects. In recent years, research on new distributed generation technologies to achieve a breakthrough, distributed generation is expected to occupy an increasingly large proportion of the electricity production. But with the large scale introduction of distributed generation, this will have a significant impact on the existing distribution system.

DG impact on the entire power system would be enormous and far-reaching. Removal of foreign influence on the structure and operation of the distribution network, the impact on power generation, transmission system will reduce the need for making new centralized power plants and remote power lines. And towards the popularity and last pattern DG electricity market will have a profound impact. First, the power company and the user form a new relationship [2]. Users can not only buy electricity from the power company, you can also use their own DG sell electricity to the power company or power company paid clipping, emergency power support services. Secondly, DG also open the door for other industries (such as natural gas company) to enter the electricity market. So the future of the electricity market competition will become more intense. 


\section{THE CONCEPT AND CLASSIFICATION OF DISTRIBUTED GENERATION}

\section{A. The Concept of Distributed Generation}

Currently, distributed generation in the international community does not have a unified standardized definition, but the basic concept is the same. Generally refers to small-scale power generation system (tens of kilowatts to tens of megawatts of small modules) decentralized arranged in the vicinity of the user, which can be economical, efficient and reliable power output of the system. Some literature also use concept of distributed resources or distributed energy resource [3]. In this paper, the use of distributed generation refers to a concept located near the user a variety of small, modular electricity production or storage technology; it follows the DG as its name. The main difference between DG and the traditional centralized power generation is its small size and close to the user, most of them can be connected with the power grid by grid devices. Generally they may supply the nearby load directly or output power to the grid as needed. The rational allocation of distributed generation into existing distribution system is the development trend of distributed power generation. It has been pointed out that by 2010 the total capacity of the new distributed generation will account for $20 \%$ of the new total power capacity.

\section{B. The Classification of Distributed Generation}

In different areas of research, DG has different classifications. According to a different energy use, it can be divided into fossil fuels, renewable energy. Depending on the different cycle ways, it can be divided into a gas turbine power generation, steam turbine generating electricity or diesel power generation. Depending on user needs, there are ways for electricity cogeneration mode and the way CCHP. If DG is connected to the power system, DG can be classified according to the type of grid technology. If DG is a rotary generator, it may sent frequency alternating current directly which belongs to the first category, like small gas turbines for power generation, geothermal power, hydropower, solar thermal power generation. Inverter type DG often refers to the DC inverter Internet the DG (such as wind power, solar power, fuel cells and a variety of energy storage technology) issued a high-frequency alternating current DG. However, in practice of the DG, taking into account the size of its DG has a direct impact in power system, so its size is divided into small (Less than 100kW), medium (100kW $1 \mathrm{MW})$, large (Above 1MW) categories.

\section{IMPACT OF DISTRIBUTED GENERATION ON DISTRIBUTION NETWORK}

Whether rural or suburban radial distribution system or city network distribution system, they design and operate based on the distribution system and the client which does not have access to any power [4]. When it accesses to a large DG in distribution system, it will have a huge impact on the structure and operation of the distribution system. Distribution network will become the network of throughout the power and interconnected user, its control and operation will be more complex. The affect of putting DG access to traditional distribution system has both positive and negative, this depends on the operating characteristics of the system and the DG. Overall positive role is mainly reflected in the improvement of system operation, efficient and reliable. However, the positive effects of this DG don't easily achieve in practice, which requires DG must have a high operational reliability, can be arbitrary scheduling, and have appropriate accessing location and capacity, also need to meet other operational constraints. Since most of the DG don't belong to Grid Company, and the use of solar energy, wind energy and other climate has a power generation characteristics of uncertainty, so these conditions are difficult to guarantee. In fact, often a number of conditions are not met, DG access cause many adverse effects on the distribution system. The following describes the main aspects of the impact of DG on the distribution network:

\section{A. Net Loss}

Distribution network loss mainly depends on power flow of the system. DG affects power flow distribution of distribution system, also will affect the loss of the distribution network. DG may increase or reduce system losses; this depends on the DG's access location, the injection capacity, its own power factor, network topology and other factors.

\section{B. Voltage Distribution}

Voltage may be maintained within the specified voltage range to ensure the power quality. Rules regulating the distribution system are based on the flow of the tide from the substation to the user. But after DG connected to the grid, the distribution system becomes more power structure from the radial structure, size and direction of the power flow may change, so that some part voltage of the power system also changes. In addition, the traditional distribution network was general radial, operating in steady state. After accessing DG, under steady-state operating conditions, because the transmission power reduction and reactive power support on the feeder, each node voltage at the load is lifted along the feeder [5].

\section{Power Quality}

After DG accesses to the distribution network, this will introduce a variety of disturbances, which have an impact on system power quality. Its influence has two main aspects. Voltage flicker: in general, we must first determine the frequency and magnitude of voltage change per unit of time, and then determine whether there is change in voltage flicker curve than the minimum threshold of visibility. If the voltage exceeds the visible changes in the minimum threshold or users of this complaint, it must take appropriate measures to solve for the problem. Voltage flicker mitigation occur include: induction motor with step-down start to reduce the starting current to reduce the possibility of the occurrence of synchronous motor voltage flicker requires more stringent synchronization and voltage matching, the inverter must limit the inrush current and output level changes. Improving power quality monitoring comparison chart shown in Fig .1. 


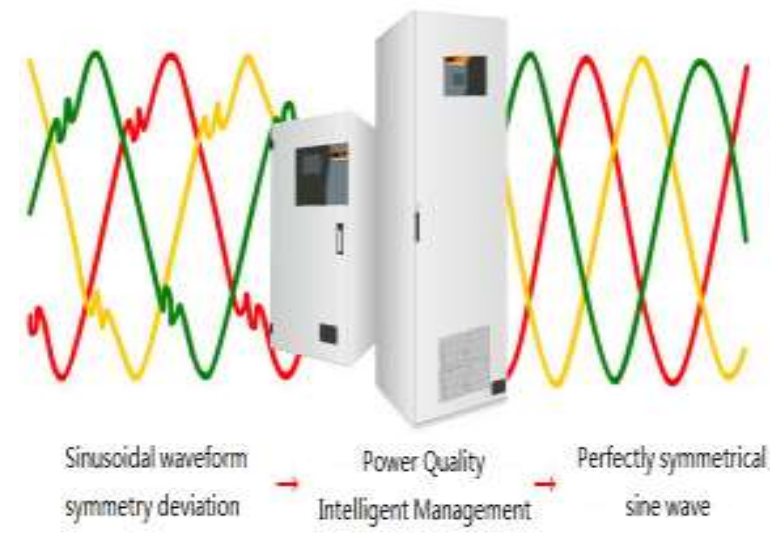

Figure 1. Improve power quality monitoring comparison chart

Simpler control voltage flicker is to limit DG DG's owner to reduce the number of starts and DG access to the distribution network through an inverter to reduce the substantial change in the output of DG. Harmonics: DG may be introduced in the following cases harmonics: DG itself is a harmonic source; DG by power electronics inverter access to distribution networks. The size and order harmonics depend on the technical and operational modes element used. In recent years, development of a semiconductor technology so that these elements can use a higher carrier frequency, so that the current waveform generated satisfies the range specified in the standard IEEE519. Currently based IGBT inverter technology has been widely used in distributed generation technologies, so we can see the development of modern electronic technology can solve the interconnection of distributed generation equipment brings the power quality problems. DG harmonic problems with it compared to other problems are not serious, but there are also some problems that must be important, such as excessive voltage distortion, resonance capacitor bank, on some issues harmonic sensitive electrical components, harmonic current causes fever makes electrical components increase at DG forced load shedding operation and so on. When DG installation needs to assess its harmonics, to determine compliance with the standard voltage distortion, harmonics are restricted or injected at DG power system. For larger units DG and situations with complex harmonic, the need for power system harmonics measurement and simulation.

\section{Short Circuit Current}

When the distribution appears network short-circuit fault, DG will provide short-circuit current. If the shortcircuit current level of the current distribution system had been close to the rated current switching device, then the fault level increasing will require increased investment of the power system cost and improve the switching equipment. Currently, some state regulations this cost is borne by the state's access to DG, which will undoubtedly limit the development of the DG [6]. Short-circuit current can be reduced by introducing into impedance between the DG and the system. Some DG connected via a transformer or reactor to the distribution network, this can increase the access resistance, but also increases the net loss and voltage fluctuations. Many countries are using an over- current limiting type of controller to limit the impact on the distribution network DG increased short circuit current.

\section{E. Relay}

The current distribution network protection system is designed in accordance with the conventional singlesupply, radiating structure. Relay Principl Schematic show in Fig .2.

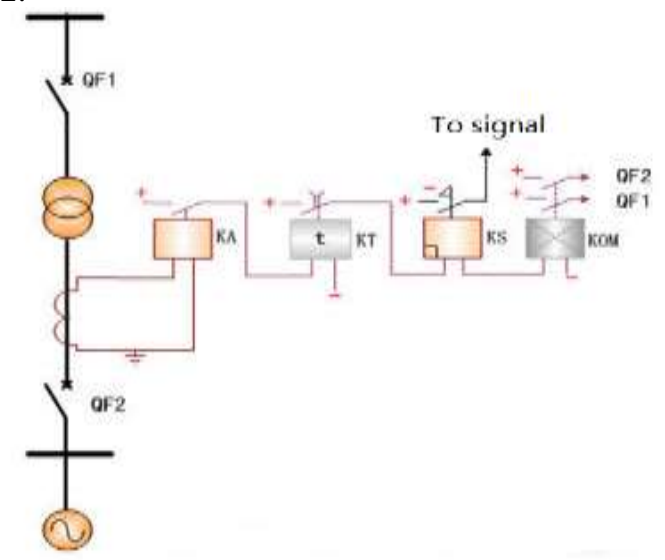

Figure 2. Relay Principl Schematic

In distribution network, a lot of protection devices already exist, it is impossible for the new DG to make huge changes, so the DG must be co-ordinated with and adapt to it[7]. However, accessing DG has to have a significant impact on distribution network failure behavior and protection features, making the original protection system is no longer fully applicable. Relay test sets of power systems show in Fig .3.

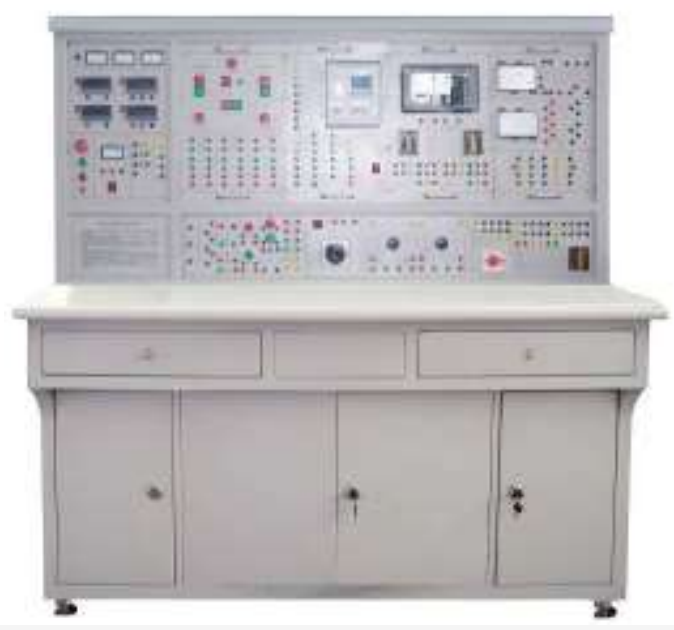

Figure 3. Relay test sets of power systems

(A) DG access after distribution lines, making the line protection or reduced sensitivity to narrow the scope of protection. In some locations the line, quick-break protection not start to form quick break protection dead zone, the line fault can not be removed. If DG and outlets located Dead quick break protection in case the system does not change the protection, overcurrent protection can only be removed by back-action failure, which increases the impact of failures on the grid. If you adjust the speed off protection setting value, it may cause speed off, unable coordination among overcurrent protection and other control devices, resulting in protection malfunction.(B) 
Adjacent line failure, DG may cause malfunction where the line protection. If a fault occurs at a distance closer to the part of the bus, the role of DG, fault current in the line to protect their lines detected value will be greater than the setting, causing a malfunction, so that the connected distributed generation line no fault trip.(C) DG reclosing will have an impact. When DG access and distribution lines, islands because if the line fault trip, formed to keep the power and voltage ratings near run, DG most likely when RECLOSURE no jump off the line, which will have two potential threats. non-reclosing year: due to loss of mains power, the power islands difficult to maintain fully synchronized with the grid, within this period of time after the power supply jump to reclose when the phase angle difference between the two may appear in the between $0^{\circ}$ and $360^{\circ}$. Under the action of this current, line protection may malfunction, leaving the reclosing lost the ability to quickly restore transient faults. fault reignition: After the loss of mains power, the fault is still maintained by the DG fault current. When reclosing, due to the power grid, and may cause fault current jump, causing reignition point of failure, leading to insulation breakdown, and further expansion of the accident[8].

\section{F . Reliability}

With the large number of access DG, DG power generation will become an important part of the total power supply system. Therefore, reliable operation of DG will be important to the power supply system reliability. If DG is only as a backup power source, it can improve the system reliability of power supply; however, if the DG run parallel with the grid and coordination is not good, it is possible to reduce the reliability of the system. Further, when the disturbance occurs in the system, DG uncertainty may also reduce the reliability of the system[9]. Currently, if the actual system disturbances occur, often it will cut all the DG and restore the system to its original structure, but this is not the best solution. When large disturbance occurs in the distribution network, you can cut a part of DG units connected with the load to ensure system stability, while ensuring appropriate DG units are still able to supply to the removed load, then the reliability of the system will be very greatly improved and the user side will get continuous power supply[10].

\section{CONCLUSION}

Faced with energy depletion and environmental pollution, human pay more attention on research and development of new DG. With the continuous improvement of the DG technologies level and equipment performance improving of a variety of DG, DG will continue to reduce costs. Moreover, with access to a large number of DG, DG grid access research will be equipped with a new direction of development of the power system. DG impact on the entire power system would be enormous and far-reaching. So the future of the electricity market competition will become more intense.

\section{ACKNOWLEDGMENT}

The authors gratefully acknowledge the contribution of co-workers and reviewers' comments.

\section{REFERENCES}

[1] Y. W. Liang and Z. J. Hu, "Summary of distributed generation in power systems and applied research," Sys.Grid.Tech, vol.27,pp.1116, May 2010

[2] R. Brown, "Impact of Smart Grid on Distribution System Design," IEEE .Pow. Ene. Soc.Gen. Meeting, vol. 17,pp.15-21, May 2008

[3] Z.G.Ru and Y.X.Dong.,"Including distributed power distribution network fault recovery strategy," Pow.Sys. Aut ,vol.10,pp.12-17, July 2009

[4] S.G.Wang, "Discussion on power system protection operation and maintenance," China.Scie.Tech. Ex..vol.33,pp.23-28, April 2010

[5] W.Y.Huang, "Operation and maintenance of power system protection," Tech.Marke, vol.7,pp.12-17, June 2011

[6] M.Wang and M.Ding. "Power distribution systems with distributed power planning," Elect.Pro,vol.8,pp.34-38, May 2010

[7] H.Y.Li, "Distributed power grid system access with the construction of technical indicators," Pop.Sci, vol.33,pp.109-115, May 2009

[8] J.L.Sun,Y.L.Li and S.W.Li, "A protection scheme for distribution system with distributed generations," Auto.Ele.Pow. Sys, vol.33,pp.81-84, May 2009

[9] Wei.Huang, J.Y.Lei and X.Xia, " Influence of distributed generation on phase-to-phase short circuit protection in distribution network," Autom.Elec.Pow.Syst, vol.32, pp.34-38, April 2008.

[10] S.W.Mohod and M.V. Aware, "Battery Energy Storage to Strengthen the Wind Generator in Integrated Power System", Jou. Elec. Sci. Tech, vol. 9, pp. 23-30,July,2009 